
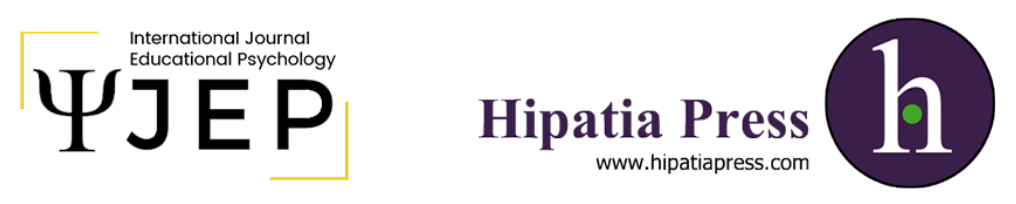

Instructions for authors, subscriptions and further details:

http://ijep.hipatiapress.com

\title{
"Einstein Worked his Socks off". Conceptions of Intelligence in University Teaching Staff
}

Jose Antonio Matias-Garcia, Rosario Cubero-Perez ${ }^{1}$

1) University of Seville (Spain)

Date of publication: June $24^{\text {th }}, 2020$

Edition period: June 2020 - October 2020

To cite this article: Matias-Garcia, J.A. \& Cubero-Perez, R. (2020).

"Einstein Worked his Socks off". Conceptions of Intelligence in University Teaching Staff. International Journal of Educational Psychology, 9(2),161194.doi: 10.17583/ijep.2020.4553

To link this article:http://dx.doi.org/10.17583/ijep.2020.4553

\section{PLEASE SCROLL DOWN FOR ARTICLE}

The terms and conditions of use are related to the Open Journal System and to Creative Commons Attribution License(CC-BY). 
June 2020 pp. 161-194

\section{"Einstein Worked his Socks off". Conceptions of Intelligence in University Teaching Staff}

Jose Antonio Matias-Garcia, University of Seville
Rosario Cubero-Perez

University of Seville

\section{Abstract}

There is vast amount of research that links implicit theories of intelligence with several learning-relevant variables in both learners and teachers alike. However, there is a gap in the literature, as there is almost no research done with university teachers. Furthermore, most scientific research polarizes incremental and fixed views of intelligence in spite of data that show there is heterogeneity in participants' views. This study explores the implicit theories of intelligence of university teachers $(\mathrm{N}=$ 20), employing a category system for the analysis of semi-structured interviews designed to capture heterogeneity. Participants were asked to express their opinion about several small vignettes regarding intelligence. The number of participants' explanations related to intelligence and the complexity in their argumentation was considered. Results show differences in both measures among different fields of knowledge and gender, but not in relation to years of teaching experience. Future implications for research, intervention, and implicit theories measurement are discussed.

Keywords: university teachers, higher education, implicit theories of intelligence, fields of knowledge, teaching experience, gender 


\section{"Einstein se Hartó de Trabajar". Concepciones de Inteligencia del Profesorado Universitario}

Jose Antonio Matias-Garcia, University of Seville

\author{
Rosario Cubero-Perez \\ University of Seville
}

\section{Resumen}

Existe una amplia investigación que relaciona las teorías implícitas de inteligencia con diversas variables vinculadas con el aprendizaje, tanto en estudiantes como en profesores. Sin embargo, encontramos un vacío en la literatura, debido a que no existe apenas investigación realizada con profesores universitarios. Además, la mayor parte de la investigación científica polariza las concepciones incrementales y fijas de la inteligencia, a pesar de los datos que demuestran la existencia de heterogeneidad en las concepciones de los participantes. Este estudio explora las teorías implícitas de inteligencia de profesores universitarios $(\mathrm{N}=20)$, empleando un sistema de categorías para el análisis de entrevistas semiestructuradas diseñadas para captar heterogeneidad en las concepciones. A los participantes se les pedía que expresaran su opinión sobre varias viñetas relacionadas con la inteligencia. Se consideró el número de explicaciones de los participantes que guardaban relación con la inteligencia y la complejidad de su argumentación. Los resultados muestran diferencias en ambas mediciones entre la rama del conocimiento y el género, pero no en cuanto a los años de experiencia en la enseñanza del profesorado universitario. Se discuten las implicaciones futuras de cara a la investigación, intervención y la medida de las teorías implícitas de la inteligencia.

Palabras clave: profesores universitarios, educación superior, teorías implícitas de inteligencia, rama del conocimiento, experiencia en la enseñanza, género 
I mplicit theories are personal beliefs that are formed through one's own personal and cultural experience (Sternberg \& Davidson, 1986). The therefore, they do not use them to consciously analyze reality. Rather, they understand reality through them (Cubero, 1996). Implicit beliefs about intelligence are related to how individuals understand their own capacities, and, therefore, constitute certain types of control beliefs (Skinner \& ZimmerGembeck, 2011). These control beliefs influence the perceived control that individuals have about the activities they are involved with and, therefore, regulate behavior, motivation, and coping mechanisms under conditions of challenge (Burnette, O’Boyle, VanEpps, Pollack, \& Finkel, 2013; Skinner \& Zimmer-Gembeck, 2011).

Dweck identifies two types of believes on intelligence: the incremental theory of intelligence (or growth mindset) postulates that intelligence can be modified through continuous effort and work, while the entity theory of intelligence (or fixed mindset) argues that intelligence is innate and cannot be modified over the course of a person's life (Dweck, 1986; Dweck, 2000; Yeager \& Dweck, 2012).

Many studies have been conducted in relation to these two types of beliefs and the repercussions that they have on people's behavior, motivation, and coping mechanisms related to the academic domain. The adscription to an incremental theory of intelligence is related to greater persistence against failure (Dweck, 1986; Renaud-Dube, Guay, Talbot, Taylor \& Koestner, 2015; Yeager \& Dweck, 2012), enhanced intrinsic motivation (Renaud-Dube et al., 2015), better academic achievement (Park et al., 2016; Yeager \& Dweck, 2012), and resilience (Yeager \& Dweck, 2012). The prior level of expertise in tasks in these individuals is not important, as they will eventually improve, attributing their successes to their efforts (Dweck, 1986; Hong, Chiu, Dweck, Lin \& Wan, 1999; Renaud-Dube et al., 2015; Robins \& Pals, 2002).

Belief in an entity theory of intelligence, on the other hand, has been linked to less achievement and persistence in difficult, initially confusing, or qualitatively new tasks (Dweck, 1986; Licht \& Dweck, 1984; Lawson, 2011; Robins \& Pals, 2002), greater extrinsic motivation (Lawson, 2011), and avoidance of difficult tasks (Dweck, 1986). In these individuals, the prior skill level will influence the tasks they engage in. They will avoid difficult tasks in 


\section{Matias-Garcia \& Cubero-Perez-Conceptions of Intelligence}

order not to fail, as they are more concerned with demonstrating their skill level than about improving it (Dweck, 1986; Lawson, 2011; Robins \& Pals, 2002).

These results are supported by several meta-analyses. Burnette et al. (2013) reported significant correlations between mindsets and self-regulatory processes, which, in turn, predicted achievement, especially in the presence of ego threat. A small direct link between mindsets and achievement have also been demonstrated in middle, high school, and college students, although it is also influenced by the cultural background of participants (Burnette, et al., 2013; Costa \& Faria, 2018; Sisk, Burgoyne, Sun, Butler, \& Macnamara, 2018). Systematic reviews and meta-analyses of mindsets interventions have shown how they are effective to improve motivation, academic achievement, and brain activity, especially in high-risk and low socioeconomic status students (Sarrasin et al., 2018; Sisk, et al., 2018).

Since these concepts guide students' learning and development, their healthy construction is of vital importance. The development of these conceptions of intelligence is influenced by the relationships and tasks students experience in their environment, right from a very young age, by means of parental or teachers' influence (Dweck, 2000; Gunderson et al., 2013; Moorman \& Pomerantz, 2010; Park et al., 2016; Yeager \& Dweck, 2012).

\section{The Concept of Intelligence among Teachers}

Teachers play an active role in the development of their student's implicit theories of intelligence. In Park et al. (2016)'s longitudinal study, the higher the teachers valued performance and final results, praising the most successful students in front of the whole class, the more students developed entity theories of intelligence. The association between teachers who placed more emphasis on learning and mastery of the topic in question, and the development of incremental theories, however, while positive, was not significant.

Teachers' theories of intelligence are also related to their teaching practice. Teachers who subscribed to an entity theory of intelligence were found to feel less responsible for the academic achievements of their students (Patterson, 
Kravchenko, Chen-Bouck, and Kelley, 2016). They are also more likely to have an outcome-based teaching style (Park et al. 2016) and to react to students' failures by consoling them for their low natural capacity, lowering both their motivation and self-efficacy (Rattan, Good \& Dweck, 2012). However, there is a positive correlation between teacher self-efficacy and incremental theories of intelligence (Strosher, 2003). This variable, which refers to teachers' confidence in their own capacity to motivate their students and help them learn and improve, is related to numerous positive results, such as persistence when dealing with students' difficulties (Gibson \& Dembo, 1984), better academic outcomes (Katz \& Stupel, 2016), and less stress in relation to teaching (Greenwood, Olejnik \& Parkay, 1990; Helms-Lorenz \& Maulana, 2016; Senler, 2016), among others.

Some research conducted in this field has found that most teachers tend to view intelligence as a modifiable characteristic (Patterson et. al., 2016; Strosher, 2003), while other articles show that teachers grant more importance to genetic influences (Antonelli-Ponti \& Crosswaite, 2019; Antonelli-Ponti, Versuti, \& da Silva, 2018), revealing inconsistent results. Science and more experienced teachers are more likely to subscribe to an entity theory of intelligence (Jonsson, Beach, Korp \& Erlandson, 2012; Lynott \& Woolfolk, 1994; Mascret, Roussel \& Cury, 2015; Strosher, 2003), although there are also inconsistencies in literature in relation to teaching experience (Patterson et. al., 2016). Regarding gender, Strosher (2003) found no significant differences between male and female teachers.

All the studies described so far were carried out with primary and secondary school students and teachers. There is a major gap in the literature as regards university teaching staff, who have, in general, followed a different career and training path from teachers working in other areas. Given the competitiveness of the university field and its specific interest in the academic world and scientific research, the profile of university teaching staff is probably different from that of primary, secondary, or high school teachers. Furthermore, university teachers are not required to gain any teacher training in order to access a teaching position, since many of them begin lecturing while still earning their PhDs. Nevertheless, they represent an important part of the educational community, and have a major influence on students' development throughout their university studies. It is also important not to 


\section{Matias-Garcia \& Cubero-Perez-Conceptions of Intelligence}

forget their role as learners, since the vast majority of university teaching staff conduct scientific research, and the acquisition and integration of new knowledge forms part of their everyday activities.

We have only found one study which explores the characteristics of implicit theories of intelligence among university faculty. Villamizar \& Donoso (2014) evaluated the implicit theories of 22 university teachers at a private university in Bucaramanga, Colombia. In this qualitative study, the authors employed individual interviews to explore teachers' views on intelligence, asking a series of direct questions about what they thought. The results revealed a wide variety of opinions related to what intelligence actually is, as well as a slight tendency to believe that it is a multiple construct. The study also found descriptions related to the idea that intelligence is something more than the results of a test. Finally, it concluded that there are no gender differences, and that the predominant view is that intelligence can be improved over time, although adults are not more intelligent than children.

\section{Measuring Implicit Theories of Intelligence}

In most of the studies found in the literature, implicit theories of intelligence are measured by means of a questionnaire containing a small number of items rated on a Likert-type scale. Respondents are asked to state the extent to which they agree with statements such as "Everyone has a certain amount of intelligence, and they can't really do much to change it" (Strosher, 2003, Bahnik \& Vranka, 2017). General items like these do not seem to capture the complex nature of implicit theories of intelligence. In the meta-analysis developed by Costa \& Faria (2018), specific implicit theories of intelligence scales showed greater association to student's academic achievement than general implicit theories of intelligence scales. Thus, contextualized assessments seem to be stronger predictors, as they are closer to the experience of participants.

Furthermore, most of the studies on this topic measure participants' adherence to one of the two types of implicit theories, as if it were a binary choice, often using a single piece of data (a number) as a measure of this adherence. This has also been highlighted by other researchers (Lüftenegger, \& Chen, 2017). In our literature review, examples of this include the studies 
by Strosher (2003), Park et al., (2016), and Bahnik \& Vranka (2017), among others. In our opinion, views on intelligence do not necessarily have to conform to one of these two opposed extremes; rather, it is entirely possible to adhere to both theories simultaneously and treat them as separate factors. In fact, according to Lüftenegger \& Chen (2017), correlations between both implicit theories vary widely (ranging from -.02 and -.78 ) and are generally too weak. Exploratory factor analysis has also revealed two distinct factors regarding both mindsets (Dupeyrat \& Mariné, 2005).

Some authors, then, recommend using specific and contextualized Likert scales and treat both mindsets as separate factors (Costa \& Faria, 2018; Lüftenegger \& Chen, 2017). Furthermore, we also believe that views on intelligence should be considered as a dynamic element which may differ from situation to situation, even within a single contextualized domain of knowledge (Cubero, Contreras, \& Cubero, 2016; Cubero, de la Mata, \& Cubero, 2008; Matias-Garcia \& Cubero-Perez, 2020), as several papers also point to. In another study using the same population and interview regarding intelligence conceptions, Matias-Garcia \& Cubero-Perez (2020) demonstrated that participants employed both incremental and entity discourse depending on the discursive context, both elicited by the interview vignettes and constructed by the participants own talk. During the course of their interviews, the university teaching staff made contradictions in their discourse, such as expressing that learning could both improve intelligence or have no relation whatsoever to it. In a series of studies conducted by Leith et al. (2014), the authors found that people strategically modified their implicit theories in accordance with specific aims and social situations, guiding the circumstances to the preferred conclusion. In another study, teachers also dynamically changed their implicit theories in accordance with the context in which children or the person assessing them were presented (Murrone and Gynther, 1991). Finally, events such as the presentation of scientific G factor theory to future teachers could increase their adherence to an entity theory of intelligence (Jonsson \& Beach, 2010).

If implicit theories of intelligence are understood as dynamic and interactive constructs which may be influenced by context, personal objectives, and even different events, then it is difficult to see how they can be faithfully reflected in a measure that is as simple as a Likert-type scale or 


\section{Matias-Garcia \& Cubero-Perez-Conceptions of Intelligence}

even a direct question about what the respondent thinks about intelligence. According to some perspectives on discursive interaction, it is necessary to analyze implicit theories from an approach of talk as contextualized actions (Cubero \& Ignacio, 2011). Both interaction and contextualization are needed for the study of implicit theories.

\section{The Present Study}

In our study, our aim was to help fill in the gap which exists in the literature regarding teaching at university, conducting a qualitative analysis of the descriptions of intelligence offered by university teaching staff during a semistructured interview in which participants were asked to give their opinion on a series of specific vignettes. Given that we view implicit theories of intelligence as being both interactive and contextualized, the specific aims of this study were as follows:

1. To explore university teaching staff's views and descriptions of intelligence.

2. To analyze the possible existence of differences in university teaching staff's discourse in accordance with their specific field of knowledge, teaching experience, and gender.

\section{Method}

\section{Participants}

Participants were selected according to three criteria: field of knowledge in which they lecture, years of teaching experience, and sex. The sample comprised 20 university teachers ( 10 men and 10 women) from the University of Seville. Four participants were selected from each field of knowledge, according to the category system in place at the university in question, namely: Arts and Humanities (A\&H), Sciences (S), Health Sciences (HS), Social and Legal Sciences (S\&LS), and Engineering and Architecture (E\&A). Also, the selection process ensured that half the participants had less than 15 years' teaching experience at the university and the other half more than 15 years' experience. The characteristics of the sample group are given in Tables 1 and 
2. The only inclusion criterion used was that the university teaching staff had to be currently lecturing at the university, regardless of their position or training.

Table 1.

Participants, variables and degrees.

\begin{tabular}{|c|c|c|c|c|}
\hline \multirow{2}{*}{$\begin{array}{l}\text { Field of } \\
\text { Knowledge }\end{array}$} & \multicolumn{2}{|c|}{ Men } & \multicolumn{2}{|c|}{ Women } \\
\hline & $>15$ & $<15$ & $>15$ & $<15$ \\
\hline $\begin{array}{l}\text { Arts and } \\
\text { Humanities }\end{array}$ & History & Fine Arts & $\begin{array}{l}\text { English } \\
\text { Studies }\end{array}$ & $\begin{array}{l}\text { Hispanic } \\
\text { Filology }\end{array}$ \\
\hline Science & Biology & Chemisty & Physics & Math \\
\hline Health Science & Psychology & Optometry & Medicine & Pharmacy \\
\hline $\begin{array}{l}\text { Social and Legal } \\
\text { Sciences }\end{array}$ & Law & $\begin{array}{l}\text { Primary } \\
\text { Education }\end{array}$ & $\begin{array}{l}\text { Labor } \\
\text { Relations }\end{array}$ & Journalism \\
\hline $\begin{array}{l}\text { Engineering and } \\
\text { Arquitecture }\end{array}$ & $\begin{array}{c}\text { Aerospace } \\
\text { Engineering }\end{array}$ & $\begin{array}{c}\text { Computer } \\
\text { Engineering }\end{array}$ & Arquitecture & $\begin{array}{c}\text { Materials } \\
\text { Engineering }\end{array}$ \\
\hline
\end{tabular}

Table 2.

Age and teacher experience in university.

\begin{tabular}{lcccc}
\hline \multirow{2}{*}{ Group } & \multicolumn{3}{c}{ Age } & Teacher Experience \\
\cline { 2 - 5 } & $M$ & $S D$ & $M$ & $S D$ \\
\hline Arts and Humanities & 40.75 & 4.99 & 13.50 & 4.43 \\
Science & 39.25 & 17.56 & 13.75 & 17.75 \\
Health Science & 43.5 & 14.11 & 16.75 & 13.30 \\
Social and Legal Sciences & 49.25 & 11.81 & 20.25 & 17.29 \\
Engineering and Arquitecture & 41 & 3.92 & 13 & 4.97 \\
$<15$ years' experience & 34.80 & 5.96 & 6.66 & 4.43 \\
>15 years' experience & 50.70 & 8.98 & 24.30 & 10.07 \\
Men & 44.80 & 11.99 & 16.10 & 13.88 \\
Women & 40.70 & 10.18 & 14.80 & 10.08 \\
Whole Sample & 42.75 & 11.03 & 15.45 & 11.82 \\
\hline
\end{tabular}




\section{Matias-Garcia \& Cubero-Perez-Conceptions of Intelligence}

\section{Instruments and Materials}

A semi-structured interview was designed, called "Views on Intelligence within the Educational Field" (VIEF, Agudelo, 2015, Camas, Caro, Matías, \& Cubero, 2015). The instrument comprises short cases or vignettes (Åkerlind, 2005; Kandemir \& Budd, 2018), highlighting different dimensions of intelligence. We identified 12 relevant dimensions in which a view on intelligence could be expressed and contextualized. They were: Control, Heredity, Effort, Culture, Training, Critical Period, Context, Expectations, Associated Qualities, People, Gender, and Diversity of Intelligence. These dimensions were selected as they have been found to be central to the scientific study of intelligence (Brinch \& Galloway, 2012; Plomin \& Von Stumm, 2018; Protzko, Aronson, \& Blair, 2013). They are also relevant in the everyday use of the concept in different contexts, such as media, family, school, etc. In total, 24 short statements about intelligence were developed, two for each of the dimensions (see Appendix A).

Authenticity in the interview is achieved by naming neutral authors and phrasing the statements in a simple way - as commonly uttered statements. The vignettes presented all followed the same structure: "A source says $+a$ statement related to intelligence". In order to avoid making it difficult for participants to contradict the statement, sources were never experts in the issue being analyzed. Examples of sources include "a blog", "a politician", "a mother", and "a popular saying". Sources were never repeated and both sexes were equally represented within a wide variety of everyday contexts. All statements contained the word "intelligence" or "intelligent", in order to elicit responses related to this concept. Finally, all statements were phrased as something that could be said by a normal person, with no specific concepts or terms from psychological literature being used. They were as similar as possible to the statements and assertions that participants would have already heard in their everyday social interactions. The instrument was designed to ensure that the responses elicited were as closely linked as possible to their everyday life.

The instrument was tested with two university professors from the Psychology Faculty and other adults from outside the teaching field. Following the pilot test, the initial position of two items and the 
phrasing of one question were modified. All interviews were digitally recorded.

The Atlas.Ti V.7 software program was used to systematize the data gathered from the interviews. This software package facilitates the analysis of complex phenomena in unstructured data sets. This program allowed us to codify our categories directly onto the interview recordings. Therefore, no prosodic information was lost, and no transcription was needed.

\section{Procedure}

In order to establish and select the sample group, potential participants were contacted through their university email addresses. All addresses were taken from the University of Seville website. Participants agreed to collaborate in the study after being informed of the objectives and the content of the interview in general terms; they did not receive any incentives. All the interviews were held in the teachers' own offices in Spanish, as it was their mother language, and lasted as much as one hour. All participants were interviewed by the same researcher, first author of this research.

Participants were asked what they thought about each vignette of the interview. In a few situations, if the response was too short or ambiguous in the interviewer's opinion, participants were asked to clarify or to expand. All participants were encouraged to freely express their opinion about each statement.

\section{Results}

A category system was built taking into account the responses of the recorded interviews. The utterances were segmented and analyzed considering the unit of meaning as the unit of analysis. A unit of meaning is a unit of discourse that contains an idea or a theme, which may or may not concur with the syntactic unit of the sentence or sentences being presented. During discourse, a new unit starts when there is a change in the theme of the content being expressed, i.e. that which is being spoken about. A sentence can contain more than one unit of meaning. 


\section{Matias-Garcia \& Cubero-Perez-Conceptions of Intelligence}

From the units of meaning extracted from the participant's responses, we constructed 116 different categories related to intelligence. These categories were later organized into 18 different topics, as several themes arose from the interviews. These topics were: Effort, Genetic Influence, Development in Non-Specific Terms, Global Environment, Formal Education, Culture, Activities, Teacher Influence, Parental Influence, Developmental Characteristics, Motivational and Emotional Influence, Others' Expectations Influence, Own Expectations Influence, Other Personal Characteristics Influence, Characteristics Associated to Intelligent People, Gender, Presence of Intelligence in Activities Outside Academic Fields, and Social and Emotional Intelligence. Most categories in this system were developed considering the participants' explicit expression of the influence or lack thereof on intelligence development of a certain activity, personal characteristic, or contextual factor. Most relevant dimensions were included in the study. The first author of the study codified all interviews. A second experimented researcher also codified $20 \%$ of the interviews in order to obtain an inter-rater reliability measure of the categorization. The Kappa Index was calculated, obtaining a value of 0.861 .

Finally, an upper-level hierarchical categorization was developed, where different categories were put together taking into account different criteria in order to obtain global results. These categories are Global Influences of Change (all categories that relate to modifiability of the intelligence), Specific Influences of Change (all categories that expresses the relation of something specific on intelligence), Non-Specific Influences of Change (all categories that expresses that intelligence can or cannot be modified, but not telling how), Individual Influences of Change (all categories related to the individual's actions and characteristics linked to intelligence malleability), Environmental Influences of Change (all categories related to the environment that may or may not affect the development of intelligence), and Total Genetic Influence (all categories related to genetic influence).

\section{Research Data}

Participants' descriptions identified influence on intelligence from several sources. Effort (70\% of participants), formal education $(65 \%)$, means and 
culture of a country (60\%), non-specific actions (they express you can do things to improve your own intelligence, but they don't specify what) (70\%), learning $(75 \%)$, instruments developed to improve your intelligence $(70 \%)$, teachers $(50 \%)$, and parents $(55 \%)$.

For instance, an A\&H participant answered in vignette 8, "I have always been told that if you set it as a goal, you can become more intelligent":

"Always, constancy and perseverance in wanting to advance and continue will always put you in a much higher spot than before."

A S participant said in vignette 16, "A child says he feels intelligent after having learned to do a new school task":

"Well, it's a way... I believe it is a way of growing your intelligence, being able to answer to new challenges. Then, if you are able to face a new challenge, a new activity, then I think you are growing an increment of your intelligence. It forms part of learning."

However, they also explicitly expressed there is not an influence from other or even the same sources, such as effort (55\%), means and culture of a country $(50 \%)$, good behavior during formal education $(80 \%)$, learning $(80 \%)$, participation in different types of activities (not related to school) (55\%), motivation and emotions (55\%), or your own expectations (55\%).

For example, an E\&A participant said in vignette 1, "A boy in his school says that his friend is very intelligent because she puts a lot of effort in everything":

"The sentence is not correct. Effort and intelligence have nothing to do with one another (...)".

A S\&LS participant said in vignette 9, "In a YouTube video it was said that people are born with a particular intelligence that can be improved or made worse depending on what happens to them during their infancy":

"I don't think so. I believe your education during infancy can have an influence in your ability to interact with other people, in your emotions, in the way you can express ideas... but your intelligence... I don't think so. You can improve what you already have. If you are motivating a child since infancy, he will more likely to be interested in culture, but if he has a limit... it doesn't matter how much you stimulate him. Yes, he will improve from his limit, but... I don't think his intelligence would develop." 


\section{Matias-Garcia \& Cubero-Perez-Conceptions of Intelligence}

Regarding the breadth of the concept of intelligence, $80 \%$ of participants associated good performance on an activity outside formal educational settings to being intelligent, while $65 \%$ of participants attributes some of those activities to simply learning or ability. Single-category data can be found in Table 3.

Table 3.

Global data of university teaching staff. Data refer to percentages of participants across the whole samples.

\begin{tabular}{|c|c|c|c|}
\hline Dimension & Identified Factor & $\begin{array}{c}\text { Explicit } \\
\text { affirmations }\end{array}$ & $\begin{array}{c}\text { Explicit } \\
\text { negations }\end{array}$ \\
\hline \multirow{2}{*}{ Effort } & Influence of Effort in Intelligence Development & $70 \%$ & $55 \%$ \\
\hline & $\begin{array}{l}\text { An Intelligent Person does not Necessarily Need } \\
\text { to Make an Effort }\end{array}$ & $95 \%$ & $0 \%$ \\
\hline \multirow{4}{*}{$\begin{array}{l}\text { Development } \\
\text { in Non- } \\
\text { Specific } \\
\text { Terms }\end{array}$} & $\begin{array}{l}\text { Development of Intelligence in Non-Specific } \\
\text { Terms }\end{array}$ & & \\
\hline & $\begin{array}{l}\text { Intelligence can be developed (in } \\
\text { general) }\end{array}$ & $45 \%$ & $25 \%$ \\
\hline & $\begin{array}{l}\text { - Intelligence can be developed with } \\
\text { limits }\end{array}$ & $30 \%$ & \\
\hline & - Intelligence is constructed & $10 \%$ & \\
\hline $\begin{array}{l}\text { Global } \\
\text { Environment }\end{array}$ & $\begin{array}{l}\text { Influence of General Environment in Intelligence } \\
\text { Development }\end{array}$ & $35 \%$ & $5 \%$ \\
\hline $\begin{array}{l}\text { Formal } \\
\text { Education }\end{array}$ & $\begin{array}{l}\text { Formal Education Influence in Intelligence } \\
\text { Development }\end{array}$ & $65 \%$ & $35 \%$ \\
\hline \multirow{2}{*}{ Culture } & $\begin{array}{l}\text { Influence of the Means and Culture of a Country } \\
\text { or Context }\end{array}$ & $60 \%$ & $50 \%$ \\
\hline & $\begin{array}{l}\text { Each Intelligence is Related to the Context in } \\
\text { which It is Used }\end{array}$ & $25 \%$ & $0 \%$ \\
\hline \multirow{3}{*}{ Activities } & $\begin{array}{l}\text { Influence of Actions (Non-Specific) in } \\
\text { Intelligence Development }\end{array}$ & $70 \%$ & $40 \%$ \\
\hline & $\begin{array}{l}\text { Influence of Good Behaviour in Intelligence } \\
\text { Development }\end{array}$ & $20 \%$ & $80 \%$ \\
\hline & $\begin{array}{l}\text { Influence of Learning New Knowledge or New } \\
\text { Abilities in Intelligence Development }\end{array}$ & $75 \%$ & $80 \%$ \\
\hline
\end{tabular}




\begin{tabular}{|c|c|c|c|}
\hline & $\begin{array}{l}\text { Influence of Participation in Different Types of } \\
\text { Activities in Intelligence Development }\end{array}$ & $35 \%$ & $55 \%$ \\
\hline & $\begin{array}{l}\text { Different Kind of Intelligences are Developed in } \\
\text { Relation to the Type of Activity that is Done }\end{array}$ & $15 \%$ & $0 \%$ \\
\hline & $\begin{array}{l}\text { Use of Instruments Developed for Improving } \\
\text { Intelligence Influence }\end{array}$ & $70 \%$ & $15 \%$ \\
\hline $\begin{array}{l}\text { Teacher } \\
\text { Influence }\end{array}$ & $\begin{array}{l}\text { Influence of Teachers in Intelligence } \\
\text { Development } \\
\text { - Cognitive Influence in Intelligence } \\
\text { - Emotional Influence in Intelligence }\end{array}$ & $\begin{array}{l}50 \% \\
40 \%\end{array}$ & $25 \%$ \\
\hline $\begin{array}{l}\text { Parental } \\
\text { Influence }\end{array}$ & $\begin{array}{l}\text { Influence of Fathers and Mothers in Intelligence } \\
\text { Development } \\
\text { - Cognitive Influence in Intelligence } \\
\text { - Emotional Influence in Intelligence } \\
\text { - Material Influence in Intelligence }\end{array}$ & $\begin{array}{c}55 \% \\
30 \% \\
5 \%\end{array}$ & $30 \%$ \\
\hline $\begin{array}{l}\text { Development } \\
\text { al } \\
\text { Characteristi } \\
\text { cs }\end{array}$ & $\begin{array}{l}\text { Possibilities of Development of Intelligence } \\
\text { Along the Whole Vital Cycle } \\
\text { Infancy is an Important Period in Intelligence } \\
\text { Development }\end{array}$ & $40 \%$ & $15 \%$ \\
\hline $\begin{array}{l}\text { Motivational } \\
\text { and } \\
\text { Emotional } \\
\text { Influence }\end{array}$ & $\begin{array}{l}\text { Influence of Motivation and Emotions in } \\
\text { Intelligence Development }\end{array}$ & $35 \%$ & $55 \%$ \\
\hline $\begin{array}{l}\text { Others' } \\
\text { Expectations } \\
\text { Influence }\end{array}$ & $\begin{array}{l}\text { Others' Expectations Influence in Intelligence } \\
\text { Development } \\
\text { Verbal Positive Reinforcement Influence in } \\
\text { Intelligence Development }\end{array}$ & $30 \%$ & $40 \%$ \\
\hline $\begin{array}{l}\text { Own } \\
\text { Expectations } \\
\text { Influence }\end{array}$ & $\begin{array}{l}\text { Influence of Your Own Expectations in } \\
\text { Intelligence Development }\end{array}$ & $20 \%$ & $55 \%$ \\
\hline $\begin{array}{l}\text { Other } \\
\text { Personal } \\
\text { Characteristi } \\
\text { cs Influence }\end{array}$ & Influence of Personality in Intelligence & $15 \%$ & $10 \%$ \\
\hline
\end{tabular}

Data of upper-level categories can be found in Table 4. Regarding Global Influences of Change, we can see that participants tended more towards 


\section{Matias-Garcia \& Cubero-Perez-Conceptions of Intelligence}

modifiability than to considering intelligence as a fixed entity. Specific Influences of Change was more frequent than Non-specific Influences of Change. Both of them tended towards modifiability. Individual Influences of Change percentages of explicit affirmations is similar to that of Environmental Influences of Change. However, the percentage of explicit negations related to Individual Influence of Change is higher, almost reaching the explicit affirmations utterances percentage and exceeding the explicit affirmations participants percentage. Almost all participants believed there is a relation between genetics and intelligence.

Table 4.

Upper-level categories. Dara related to the whole sample.

\begin{tabular}{|c|c|c|c|c|}
\hline & \multicolumn{2}{|c|}{ Explicit affirmations } & \multicolumn{2}{|c|}{ Explicit Negations } \\
\hline $\begin{array}{l}\text { Upper-Level } \\
\text { Categories }\end{array}$ & $\begin{array}{l}\text { Percentage of } \\
\text { Utterances }\end{array}$ & $\begin{array}{l}\text { Percentage of } \\
\text { Participants }\end{array}$ & $\begin{array}{c}\text { Percentage of } \\
\text { Utterances }\end{array}$ & $\begin{array}{c}\text { Percentage of } \\
\text { Participants }\end{array}$ \\
\hline $\begin{array}{l}\text { Global Influences } \\
\text { of Change }\end{array}$ & $32 \%$ & $100 \%$ & $17 \%$ & $95 \%$ \\
\hline $\begin{array}{l}\text { Specific Influences } \\
\text { of Change }\end{array}$ & $23 \%$ & $95 \%$ & $15 \%$ & $95 \%$ \\
\hline $\begin{array}{l}\text { Non-Specific } \\
\text { Influences of } \\
\text { Change }\end{array}$ & $9 \%$ & $85 \%$ & $2 \%$ & $50 \%$ \\
\hline $\begin{array}{l}\text { Individual } \\
\text { Influence of } \\
\text { Change }\end{array}$ & $14 \%$ & $90 \%$ & $12 \%$ & $95 \%$ \\
\hline $\begin{array}{l}\text { Environmental } \\
\text { Influence of } \\
\text { Change }\end{array}$ & $12 \%$ & $90 \%$ & $4 \%$ & $60 \%$ \\
\hline $\begin{array}{l}\text { Total Genetic } \\
\text { Influence }\end{array}$ & $8 \%$ & $95 \%$ & $1 \%$ & $20 \%$ \\
\hline
\end{tabular}


Most relevant data related to fields of knowledge, years of teaching experience, and sex is presented. Regarding the most global upper-level category, Global Influence of Change, the A\&H, S, and HS groups showed similar profiles according to the percentages of explicit affirmative and negative utterances $(39 \%$ and $11 \%, 44 \%$ and $14 \%$, and $39 \%$ and $12 \%$, respectively). The S\&LS and E\&A groups presented mixed profiles, being the E\&A group more oriented to the absence of change (25\% and $21 \%$, and $18 \%$ and $25 \%$, respectively). Concerning the upper-level category Total Genetic Influence, the HS and S\&LS groups displayed the lowest values of percentage of affirmative utterances ( $5 \%$ and $5 \%$, respectively), the E\&A group those highest (12\%), and the A\&H and S groups exhibited intermediate values $(9 \%$ and $8 \%$, respectively). Only in the HS and S\&LS groups ever appeared explicit negative utterances that expressed there is not a direct relation of genetics on intelligence ( $1 \%$ and $2 \%$, respectively).

Differences between more and less than 15 years' experience in global terms were minimal in the percentage of explicit affirmative and negative utterances in Global Influence of Change (32\% and $15 \%$, and $33 \%$ and $18 \%$, respectively) and Total Genetic Influence (8\% and $1 \%$, and $8 \%$ and $1 \%$, respectively).

However, there were differences between men and women in both upperlevel categories. The men expressed more explicit affirmative utterances and less explicit negative utterances towards modifiability of intelligence than women $(42 \%$ and $13 \%$, and $23.5 \%$ and $20 \%$, respectively). They also presented fewer affirmative utterances related to the role of genetic influence than women (6\% and $1 \%$, and $9 \%$ and $1 \%$, respectively).

Finally, in order to analyze the complexity and width of the responses of the participants, the Frequency of Different Categories will be considered regarding the widest upper-level category, Global Influence of Change, which refers to the stability or modifiability of intelligence in all categories related to intelligence. A bigger number in this variable meant more different descriptions were presented and more elements were identified in their interviews as related or not with intelligence, thus presenting more complexity in their discourse. In general, all groups displayed higher complexity towards modifiability than to non-modifiability, except for the E\&A group. The A\&H, 
S, and HS groups showed high complexity towards change, while S\&LS and E\&A groups exhibited high complexity towards non-modifiability. Considering teaching experience, results were similar for both groups. Regarding sex, the women tended to have less complexity towards change and more towards non-change than men. Table 5 shows all data of our groups' Frequency of Different Categories.

Table 5.

Means and standard deviations of the frequency of different categories in groups.

\begin{tabular}{lcccc}
\hline & \multicolumn{3}{c}{ Explicit affirmations } & \multicolumn{2}{c}{ Explicit Negations } \\
\hline Groups & $M$ & $S D$ & $M$ & $S D$ \\
\hline Arts and Humanities & 15,25 & 6,70 & 5,5 & 4,20 \\
Science & 15 & 5,29 & 6 & 2,94 \\
Health Science & 15,5 & 7,55 & 5,25 & 4,57 \\
Social and Legal Sciences & 11 & 8,76 & 7,25 & 7,5 \\
Engineering and Arquitecture & 5,75 & 8,18 & 9,75 & 4,57 \\
Less than 15 Years Exp. & 12,7 & 7,65 & 7,3 & 5,06 \\
More than 15 Years Exp. & 12,3 & 8,00 & 6,2 & 4,61 \\
Men & 14,4 & 7,57 & 5,4 & 4,20 \\
Women & 10,6 & 7,56 & 8,1 & 5,09 \\
Global & 12,5 & 7,62 & 6,75 & 4,74 \\
\hline
\end{tabular}

\section{Discussion}

This study analyzed the views held by university teaching staff regarding intelligence, using a semi-structured interview which presented a series of vignettes upon which participants were invited to freely comment. The content of the interviews was later analyzed using a category system. Implications for university teachers' implicit theories understanding, intervention, and measurement will be discussed next.

When the results were compared in accordance with the field of knowledge, it was found that, at a global level, participants from the $\mathrm{A} \& \mathrm{H}, \mathrm{S}$, 
and HS fields gave more numerous and more complex explanations and descriptions linked to the change or modification of intelligence, while those from S\&LS field gave mixed descriptions. This may be due to the fact that this last group itself was very heterogeneous. S\&LS includes degrees whose content is closely linked to the issue being studied here, such as Primary Education studies, as well as degrees focusing on areas far removed from human development and learning. Lastly, those from the field of E\&A gave more numerous and more varied explanations for the lack of change in intelligence. As regards genetic influence, those from the HS and S\&LS fields tended to minimize the importance of this aspect, since it was mentioned less often by these participants. Those from the field of E\&A attached most importance to genetic influence. The category "Genetics does not directly determine intelligence", which refers to statements about total potential for any activity from birth, or the interaction between genetics and environment, reaffirms these findings, since it was only mentioned by some participants from the HS and S\&LS fields. These results coincide with those found by previous studies, which reported that individuals studying degrees related to mathematics and science are more likely to subscribe to an entity theory of intelligence (Jonsson et al., 2012; Mascret et al., 2015).

As explained before in Research Data, at a global level, the different groups formed on the basis of years of teaching experience were fairly similar as regards the strength of the relationship and the complexity of the arguments posed. This finding complements those reported by previous studies of teachers from different educational levels, where some of them found differences regarding teaching experience (Lynott \& Woolfolk, 1994; Strosher, 2003), while others did not (Patterson et. al., 2016).

However, major differences were found between men and women. In general, women systematically demonstrated a greater tendency than men to subscribe to an entity theory of intelligence in all the variables studied. Complexity towards change was lower, while complexity towards no change was higher (Table 5). Categories related to genetic influence also appeared more often in women's discourse. These findings contradict those that reported for secondary school teachers by Strosher (2003) and university teachers by Villamizar \& Donoso (2014), who found no differences between men and women. Additional research is needed to clarify why these 


\section{Matias-Garcia \& Cubero-Perez-Conceptions of Intelligence}

differences might occur, as there are no studies that further analyze these gender differences. However, some studies have found an association between academically brilliant female students and entity beliefs of intelligence, but not in academically brilliant male students (Leggett, 1985; Licht \& Dweck, 1984), which could be related to these results. Also, we could refer to gender stereotypes in STEM areas (Kim, Sinatra, \& Seyranian, 2018) and the attributional gender bias regarding effort and ability, by which teachers (Espinoza, Fontes, \& Arms-Chavez, 2014; Tiedemann, 2000), parents (Yee \& Eccles, 1988), and students (Dickhäuser \& Meyer, W., 2006) attribute successes and failures differently to boys and girls. This is a line of research that needs to be further developed.

The results of the study also revealed which aspects interventions regarding university teaching staff's intelligence beliefs should concentrate on. Working on elements that, in scientific research, are related to a greater development of intelligence would enable university teachers to become more aware of what is relevant to their own learning and development, as well as the learning and development of their students. As mentioned before, teachers' theories of intelligence are related to their teaching practice, instructional approach, and didactical conceptions (Park et al., 2016; Patterson et. al., 2016; Rattan et al., 2012; Strosher, 2003). An intervention would enable them to achieve greater perceived control over the activities in which they participate on a daily basis regarding their role as teachers, learners, and researchers (Burnette et al., 2013; Sarrasin et al., 2018; Skinner \& ZimmerGembeck, 2011; Strosher, 2003).

One clear and relevant focus of attention in our participants is a seemingly generalized view that emotions and motivation (55\%) and one's own expectations (55\%) do not influence the development of intelligence. Prior research has shown that these variables are of vital importance to academic and cognitive development (Alesi, Rappo \& Pepi, 2016; Kriegbaum, Jansen \& Spinath, 2015). Although both individual and environmental positive influence percentages are similar, the increased percentages related to the lack of individual influences on intelligence points to another relevant focus of attention regarding intervention. Although environmental influences are important, individual actions and characteristics are more controllable and modifiable by both students and teachers. Interventions towards thisentity 
implicit theory discourse would probably result in more perceived control (Skinner \& Zimmer-Gembeck, 2011). In addition, those who would benefit most from an intervention on these views are university teaching staff in the field of E\&A, due to the many different factors that they rejected as influencing the development of intelligence. It may be possible in this way to improve the academic results obtained in E\&A degrees, which have the highest dropout rate in the whole Spanish university system (Ministerio de Educación y Formación Profesional, 2015). Furthermore, female university teaching staff also tended to subscribe more to entity descriptions in our data. If these results are confirmed in future studies, then, gender would also be a variable to be taken into consideration regarding the concept of intelligence among university teaching staff.

Finally, there are relevant implications to implicit theories measurement. First, the way in which the descriptions given are expressed is important to consider. When general or vague statements were made about intelligence ("A not particularly intelligent person may develop their intelligence", "I simply don't believe all that about people being born with something static"), these statements were more likely to be oriented towards development than more specific assertions ("Effort has nothing to do with intelligence", "Schools have a major influence (on intelligence), about $90 \%$ I would say"). After asserting that intelligence in general could be developed, when asked to go into more detail, some participants systematically rejected the role of numerous factors, contexts, and activities as having any influence whatsoever. In the case of women, this relationship was even inverted. Women's percentage of affirmative utterances in Non-Specific Influence of Change $(7 \%)$ was higher than those that were negative $(3 \%)$, while in Specific Influence of change negative utterances, it was higher (17\%) than those that were positive (16.5\%). Most general and non-specific statements made by women about intelligence were more oriented towards change, while their specific assertions were more oriented towards non-modifiability. This inversion was not found in men, although there was also an increase in the negative side of the Specific influence in relation to its Non-Specific counterpart. This has important implications for how the so-called implicit theories should be assessed. As mentioned earlier, much of the research conducted to date has, like Strosher (2003), used questionnaires containing a 


\section{Matias-Garcia \& Cubero-Perez-Conceptions of Intelligence}

series of general statements with no context, rated on a Likert-type scale, similar to those Non-Specific utterances, maybe presenting a bias. Other studies also support our results. As mentioned earlier, Costa \& Faria (2018) demonstrated in their meta-analytic review that general scales present weaker correlations to relevant variables such as academic achievement than specific scales. Thus, the instruments used should be as contextualized and specific as possible, in order to determine what kind of ideas emerge in the context being studied.

It should also be noted that, on numerous occasions, when the percentage of participants for both explicit affirmations and negations are added together, the result is more than $100 \%$ (Table 3 ). This is due to the fact that some people expressed one opinion at one point in the interview, and then the opposite opinion later on. One example of this is in the effort related categories, in which $70 \%$ of participants explicitly stated that effort influences intelligence, while at the same time $55 \%$ of them also explicitly stated that it does not. This happened on multiple occasions and with different categories (Table 3). As mentioned before, people hold a wide range of different views about intelligence, and one idea may exist simultaneously with its complete opposite, its emergence determined by other factors such as discursive context. Nevertheless, in this study it was not necessary to intentionally and experimentally manipulate the theories, as in the studies by Leith et al. (2014). Rather, views emerged naturally throughout the course of a conversation about everyday cases linked to intelligence. By considering implicit theories as separate factors, we did not mask this heterogeneity, as other previous studies might have done. Our data support the idea that both incremental and fixed beliefs constitute separate factors (Lüftenegger \& Chen, 2017). In Matias-Garcia \& Cubero (2020), further analysis regarding university teaching staff heterogeneous conceptions of intelligence can be found.

Lüftenegger \& Chen (2017) claimed that most incremental and entity theories are observed using explicit measures. We believe our methodology constitutes an alternative to these traditional models. By making participants discuss everyday statements or vignettes, they employed their own discourse and previous experiences related to intelligence conceptions. We did not ask them directly what they thought about intelligence or which was their level of 
agreement with previously designed items (as in Likert scales). Rather, we asked them to use their implicit knowledge to discuss relevant small stories, answering to specific agents, such as mothers (Vignette 3), teachers (Vignette 24), or politicians (Vignette 11). During the conversation, they were able to introduce their own words and personal anecdotes, which served both as the final study data and as a more ecological contextualization of their subsequent talk, which could not be introduced by researchers. This methodology proved useful for capturing heterogeneity in their conceptions as well, as our participants were able to reflect contradictory views without them even realizing. The interactional nature of the interview, the presentation of different every day stories, and the fact that we did not ask them directly what they thought about intelligence allowed us to research implicit theories in discursive contexts which make use of sentences that could be familiar in participants' everyday life (Cubero \& Ignacio, 2011).

As regards the limitations of the study, our participants were only a small sample within a very diverse and broad-ranging population (i.e. university faculty). This, along with the qualitatively descriptive nature of our analysis, makes it difficult to generalize to the whole population of university teaching staff. In order to achieve generalizability, more participants should be studied, and a quantitatively statistical approach should be followed. Specific gender studies must also be developed. The inclusion of new samples must consider different areas of expertise, not only for increasing representation in the university teacher population, but for providing university teachers with data related to their specific degrees. This would improve future interventions as we can give them examples they could recognize in their own experience. Furthermore, studies that address other populations' heterogeneity, such as learners or school teachers, may be useful to better characterize implicit theories of intelligence and how they interact with their environment in more depth.

\section{Conclusions}

The present study evaluated ideas regarding intelligence among university teaching staff (a field that has hardly been studied at all) through a semistructured interview. Detailed profiles were developed for each group, in 


\section{Matias-Garcia \& Cubero-Perez-Conceptions of Intelligence}

accordance with field of knowledge, years of teaching experience, and sex. These profiles may prove useful for broader research studies and future interventions on this forgotten population, whose characteristics are different from those of other educators. Our results highlight the importance of considering both incremental and fixed theories as separate factors, as well as the need for conducting a more specific and contextualized evaluation of descriptions and views of intelligence, given both the heterogeneous and dynamic nature of the participants' beliefs and the key role played by context of meaning.

\section{Acknowledgements}

Special thanks to the contributions in language revision of translator Diego Luque de la Campa, PhD student Maria del Carmen Ocaña, and Medicine student Carolina Torregrosa

\section{References}

Alesi, M., Rappo, G., \& Pepi, A. (2016). Investigating the Improvement of Decoding Abilities and Working Memory in Children with Incremental or Entity Personal Conceptions of Intelligence: Two Case Reports. Frontiers in Psychology, 6. http://doi.org/10.3389/fpsyg.2015.01939

Agudelo, A.I. (2015). Conceptions of Intelligence within the Educational Environment: Teachers' Implicit Theories. Unpublished document. Department of Developmental and Educational Psychology. University of Seville.

Åkerlind, G.S. (2005). Academic growth and development - How do university academics experience it? Higher Education, 50(1), 1-32. https://doi.org/10.1007/s10734-004-6345-1

Antonelli-Ponti, M., \& Crosswaite, M. (2019). Teachers' perceptions about the etiology of intelligence and learning difficulties. International Journal of Educational Psychology, 8(2), 162-187.

Antonelli-Ponti, M., Versuti, F. M., \& da Silva, J. A. (2018). Teachers' perception about genes and behavior. Estudos de Psicologia (Campinas), 35(4), 421-431. 
Bahník, Š., \& Vranka, M. A. (2017). Growth mindset is not associated with scholastic aptitude in a large sample of university applicants. Personality and Individual Differences, 117, 139-143. https://doi.org/10.1016/J.PAID.2017.05.046

Brinch, C.N., \& Galloway, T.A. (2012). Schooling in adolescence raises IQ scores. Proceedings of the National Academy of Sciences of the United States of America, 109, 425-430. https://doi.org/10.1073/pnas.1106077109

Burnette, J. L., O'Boyle, E. H., VanEpps, E. M., Pollack, J. M., \& Finkel, E. J. (2013). Mind-sets matter: A meta-analytic review of implicit theories and self-regulation. Psychological bulletin, 139(3), 655-701. https://doi.org/10.1037/a0029531

Camas, L., Caro, C., Matías, J., \& Cubero, R (2015). Interview script instrument "Concepciones de la inteligencia en el ámbito educativo" (CIAE). In Matías, J.A. (2016), "Pero Einstein se hartó de trabajar". Concepciones de inteligencia en el profesorado universitario. Master Dissertation. Department of Developmental and Educational Psychology. University of Seville.

Costa, A., \& Faria, L. (2018). Implicit theories of intelligence and academic achievement: A meta-analytic review. Frontiers in psychology, 9, 829. https://doi.org/10.3389/fpsyg.2018.00829

Cubero, M., Contreras, R., \& Cubero, R. (2016). Cultural origins and schooling influence on scientific and everyday concepts: The case of border and citizen on the border concepts. Culture \& Psychology, 22 (2), 182-205. https://doi.org/10.1177/1354067X15601189

Cubero, M., de la Mata. M.L., \& Cubero, R. (2008). Activity settings, discourse modes and ways of understanding: On the heterogeneity of verbal thinking. Culture \& Psychology, 14 (4), 403-430.

Cubero, R. (1996). Concepciones de los alumnos y cambio conceptual: un estudio longitudinal sobre el conocimiento del proceso digestivo en Educación Primaria (Doctoral dissertation). University of Seville.

Cubero, R. \& Ignacio, M.J. (2011). Accounts in the Classroom: Discourse and the Coconstruction of Meaning. Journal of Constructivist Psychology, 24(3), 234-267.

Dickhäuser, O., \& Meyer, W. (2006). Gender differences in young children's math ability attributions. Psychology Science, 48(1), 3-16. 


\section{Matias-Garcia \& Cubero-Perez-Conceptions of Intelligence}

Dupeyrat, C., \& Mariné, C. (2005). Implicit theories of intelligence, goal orientation, cognitive engagement, and achievement: A test of Dweck's model with returning to school adults. Contemporary Educational Psychology, 30(1), 43-59.

Dweck, C. S. (1986). Motivational processes affecting learning. American Psychologist, 41(10), 1040-1048. http://doi.org/10.1037/0003066X.41.10.1040

Dweck, C. (2000). Self-theories: Their Role in Motivation, Personality, and Development. Psychology Press.

Espinoza, P., Fontes, A. B. A. da L., \& Arms-Chavez, C. J. (2014).

Attributional gender bias: teachers' ability and effort explanations for students' math performance. Social Psychology of Education, 17(1), 105-126. http://doi.org/10.1007/s11218-013-9226-6

Gibson, S., \& Dembo, M. H. (1984). Teacher Efficacy: A Construct

Validation. Journal of Educational Psychology, 76(4), 569-82.

https://doi.org/10.1037/0022-0663.76.4.569

Greenwood, G. E., Olejnik, S. F., \& Parkay, F. W. (1990). Relationships between Four Teacher Efficacy Belief Patterns and Selected Teacher

Characteristics. Journal of Research and Development in Education, 23(2), 102-106.

Gunderson, E. A., Gripshover, S. J., Romero, C., Dweck, C. S., GoldinMeadow, S., \& Levine, S. C. (2013). Parent Praise to 1- to 3-YearOlds Predicts Children's Motivational Frameworks 5 Years Later. Child Development, 84(5), 1526-1541.

http://doi.org/10.1111/cdev.12064

Helms-Lorenz, M., \& Maulana, R. (2016). Influencing the psychological well-being of beginning teachers across three years of teaching: selfefficacy, stress causes, job tension and job discontent. Educational Psychology, 36(3), 569-594.

http://doi.org/10.1080/01443410.2015.1008403

Hong, Y. Y., Chiu, C. Y., Dweck, C. S., Lin, D. M. S., \& Wan, W. (1999).

Implicit theories, attributions, and coping: A meaning system approach. Journal of Personality and Social Psychology, 77(3), 588599. http://dx.doi.org/10.1037/0022-3514.77.3.588

Jonsson, A.C., \& Beach, D. (2010). Reproduction of Social Class in Teacher Education: The Influence of Scientific Theories on Future Teachers' 
Implicit Beliefs. Journal for Critical Education Policy Studies, 8(2), $1-46$.

Jonsson, A.C., Beach, D., Korp, H., \& Erlandson, P. (2012). Teachers' implicit theories of intelligence: influences from different disciplines and scientific theories. European Journal of Teacher Education, 35(4), 387-400. https://doi.org/10.1080/02619768.2012.662636

Kandemir, A., \& Budd, R. (2018). Using vignettes to explore reality and values with young people. Forum: Qualitative Social Research, 19(2). http://dx.doi.org/10.17169/fqs-19.2.2914

Katz, S., \& Stupel, M. (2016). Enhancing elementary-school mathematics teachers' efficacy beliefs: a qualitative action research. International Journal of Mathematical Education in Science and Technology, 47(3), 421-439. http://doi.org/10.1080/0020739X.2015.1080314

Kim, A. Y., Sinatra, G. M., \& Seyranian, V. (2018). Developing a STEM Identity Among Young Women: A Social Identity Perspective. Review of Educational Research, 88(4), 589-625. https://doi.org/10.3102/0034654318779957

Kriegbaum, K., Jansen, M., \& Spinath, B. (2015). Motivation: A predictor of PISA's mathematical competence beyond intelligence and prior test achievement. Learning and Individual Differences, 43, 140-148. http://doi.org/10.1016/j.lindif.2015.08.026

Lawson, R. J. (2011). Concepts of ability and their effect on approaches to learning and motivational orientation. International Review of Social Sciences and Humanities, 1(1), 30-46. Research Online University of Wollongong:

https://ro.uow.edu.au/cgi/viewcontent.cgi?referer=https://www.google $. \operatorname{com} / \&$ httpsredir $=1 \&$ article $=1523 \&$ context=asdpapers

Leggett, E. (1985). Children's entity and incremental theories of intelligence: Relationships to achievement behavior. Paper presented at the meeting of the Eastern Psychological Association, Boston.

Leith, S. A., Ward, C. L. P., Giacomin, M., Landau, E. S., Ehrlinger, J., \& Wilson, A. E. (2014). Changing Theories of Change: Strategic Shifting in Implicit Theory Endorsement. Journal of Personality and Social Psychology, 107(4), 597-620. http://doi.org/10.1037/a0037699

Licht, B. G., \& Dweck, C. S. (1984). Determinants of academic achievement: The interaction of children's achievement orientations 
188 Matias-Garcia \& Cubero-Perez-Conceptions of Intelligence

with skill area. Developmental Psychology, 20(4), 628-636.

http://doi.org/10.1037/0012-1649.20.4.628

Lynott, D. J., \& Woolfolk, A. E. (1994). Teachers' implicit theories of intelligence and their educational goals. The Journal of Research and Development in Education, 27(4), 253-264.

Lüftenegger, M., \& Chen, J. A. (2017). Conceptual issues and assessment of implicit theories. Zeitschrift für Psychologie, 255(2), 99-106.

https://doi.org/10.1027/2151-2604/a000286

Mascret, N., Roussel, P., \& Cury, F. (2015). Using implicit measures to highlight science teachers' implicit theories of intelligence. European Journal of Psychology of Education, 30(3), 269-280.

http://doi.org/10.1007/s10212-015-0249-6

Matias-Garcia, J.A. \& Cubero-Perez, R. (2020). Heterogeneity in the conceptions of intelligence of university teaching staff. Culture \& Psychology. https://doi.org/10.1177/1354067X20936926

Ministerio de Educación y Formación Profesional (2015). Datos y Cifras del Sistema Universitario Español. Curso 2014-2015. Subdirección General de Documentación y Publicaciones. Ministerio de Educación y Formación Profesional:

https://www.educacionyfp.gob.es/dam/jcr:aa35d8fe-ffbd-4142-8cca9a093cc1d9de/datos-y-cifras-del-sue-curso-2014-2015.pdf

Moorman, E. A., \& Pomerantz, E. M. (2010). Ability mindsets influence the quality of mothers' involvement in children's learning: an experimental investigation. Developmental Psychology, 46(5), 13541362. http://doi.org/10.1037/a0020376

Murrone, J., \& Gynther, M. (1991). Teachers Implicit Theories of Childrens Intelligence. Psychological Reports, 69(3), 1195-1201. https://doi.org/10.2466/pr0.1991.69.3f.1195

Park, D., Gunderson, E. A., Tsukayama, E., Levine, S. C., \& Beilock, S. L. (2016). Young Children's Motivational Frameworks and Math Achievement: Relation to Teacher-Reported Instructional Practices, but Not Teacher Theory of Intelligence. Journal of Educational Psychology, 108(3), 300-313. http://doi.org/10.1037/edu0000064 Patterson, M. M., Kravchenko, N., Chen-Bouck, L., \& Kelley, J. A. (2016). General and domain-specific beliefs about intelligence, ability, and effort among preservice and practicing teachers. Teaching and 
Teacher Education, 59, 180-190.

https://doi.org/10.1016/j.tate.2016.06.004

Plomin, R., \& von Stumm, S. (2018). The new genetics of intelligence.

Nature Reviews Genetics, 19, 148-159.

http://doi.org/10.1038/nrg.2017.104

Protzko, J., Aronson, J., \& Blair, C. (2013). How to make a young child smarter: Evidence from the database of raising intelligence.

Perspectives on Psychological Science, 8, 25-40.

https://doi.org/10.1177/1745691612462585

Rattan, A., Good, C., \& Dweck, C. S. (2012). 'It's ok — Not everyone can be good at math': Instructors with an entity theory comfort (and demotivate) students. Journal of Experimental Social Psychology, 48(3), 731-737. http://doi.org/10.1016/j.jesp.2011.12.012

Renaud-Dube, A., Guay, F., Talbot, D., Taylor, G., \& Koestner, R. (2015).

The relations between implicit intelligence beliefs, autonomous academic motivation, and school persistence intentions: a mediation model. Social Psychology of Education, 18(2), 255-272.

http://doi.org/10.1007/s11218-014-9288-0

Robins, R. W., \& Pals, J. L. (2002). Implicit Self-Theories in the Academic Domain: Implications for Goal Orientation, Attributions, Affect, and Self-Esteem Change. Self and Identity, 1(4), 313-336.

http://doi.org/10.1080/15298860290106805

Sarrasin, J. B., Nenciovici, L., Foisy, L.-M. B., Allaire-Duquette, G., Riopel, M., \& Masson, S. (2018). Effects of teaching the concept of neuroplasticity to induce a growth mindset on motivation, achievement, and brain activity: A meta-analysis. Trends in Neuroscience and Education, 12, 22-31. https://doi.org/10.1016/J.TINE.2018.07.003

Senler, B. (2016). Pre-service science teachers' self-efficacy: The role of attitude, anxiety and locus of control. Australian Journal of Education, 60(1), 26-41. http://doi.org/10.1177/0004944116629807

Sisk, V. F., Burgoyne, A. P., Sun, J., Butler, J. L., \& Macnamara, B. N. (2018). To what extent and under which circumstances are growth mind-sets important to academic achievement? Two meta-analyses. Psychological science, 29(4), 549-571. https://doi.org/10.1177/0956797617739704 
Skinner, E., \& Zimmer-Gembeck, M. (2011). Perceived Control and the Development of Coping. In S. Folkman (Ed.), The Oxford Handbook of Stress, Health, and Coping. Oxford University Press.

Sternberg, R. J. \& Davidson, J. E. (1986). Conceptions of giftedness: A map of the terrain. Cambridge University Press.

Strosher, H. L. W. (2003). Prospective and practicing teachers' beliefs: a study of implicit theories of intelligence and teacher efficacy (Doctoral dissertation). University of Victoria.

Tiedemann, J. (2000). Gender-related beliefs of teachers in elementary school mathematics. Educational Studies in Mathematics, 41(2), 191207. http://doi.org/10.1023/A:1003953801526

Villamizar, G., \& Donoso, R. (2014). Teorías implícitas sobre inteligencia de profesores universitarios. Educere, 18(59), 103-110. Dialnet: https://dialnet.unirioja.es/servlet/articulo? codigo $=6502211$

Yeager, D. S., \& Dweck, C. S. (2012). Mindsets That Promote Resilience:

When Students Believe That Personal Characteristics Can Be Developed. Educational Psychologist, 47(4), 302-314. https://doi.org/10.1080/00461520.2012.722805

Yee, D., \& Eccles, J. S. (1988). Parent perceptions and attributions for children's math achievement. Sex Roles, 19, 317-333. https://doi.org/10.1007/bf00289840 


\section{Appendix A}

\section{PROJECT: “CONCEPTIONS OF INTELLIGENCE IN THE} EDUCATIONAL FIELD. UNIVERSITY TEACHER'S IMPLICIT THEORIES" (VIEF)

Age: ___ Sex: Field of Knowledge:

Teaching experience:

Date:

Interviewer:

We are doing a research about different educational topics. Now, we are going to present you a series of hypothetical cases in which we will ask your opinion about what is being stated in them. We thank your collaboration and your help in the building of knowledge. Once you are ready, we can start the interview.

1. A boy in his school says that his friend is very intelligent because she puts a lot of effort in everything. (Effort Dimension)

2. On television, an educational game for improving intelligence in boys and girls, which consists of doing certain activities, has being announced. (Training Dimension). 


\section{Matias-Garcia \& Cubero-Perez-Conceptions of Intelligence}

3. My neighbor says that her daughter of 4 years-old is not so intelligent, but as she is going to start infant school, she thinks her daughter will improve. (Context Dimension)

4. A collection of proverbs says that you can't be made intelligent; you need to be born intelligent. (Heredity Dimension)

5. In general, people think intelligent people have many friends. (Associated Qualities Dimension)

6. Praising children by acknowledging their brilliance can make their intelligence to be improved. (Expectations Dimension)

7. My cousin, who works in a motorcycle workshop, says he is very intelligent because he is capable of assembling and disassembling a motorcycle in an afternoon. (Diversity of Intelligence Dimension)

8. I have always been told that if you set it as a goal, you can become more intelligent. (Control Dimension)

9. In a Youtube video, it was said that people are born with a certain intelligence that can be improved or made worse depending on what happens to them during their infancy (Critical Period Dimension)

10. I have watched an interview in which a mother says her son doesn't make any effort, nor study and even so, obtains the best scores in his class because he is very intelligent. (Effort Dimension)

11. A politician says African children who live in impoverished environments will never become as intelligent as children who live in developed countries. (Culture Dimension) 
12. A mother says she signs her son up for computer, painting, and horse riding classes so they will make him more intelligent (Context Dimension)

13. My grandma says women can become as intelligent as men if they strive for it. (Gender Dimension)

14. A father says to her daughter that whatever she does won't change her intelligence (Control Dimension)

15. According to my teacher, Einstein was a very intelligent person, and all his achievements were not because of his effort, but because he was born with the gift of intelligence. (Heredity Dimension)

16. A child says he feels intelligent after having learned to do a new school task. (Training Dimension)

17. In the radio, it has been said that Finnish children are more intelligent because they live in a more developed society. (Culture Dimension)

18. My teachers have always told us intelligence and good behavior belong together. (Associated Qualities Dimension)

19. My friend José says that in our species men are more intelligent than women. (Gender Dimension)

20. In Facebook, a secondary education student writes: 'If you believe you are intelligent, you'll finally become an intelligent person, even though you were not'. (Expectations Dimension)

21. An adolescent says he is very intelligent because he knows how to draw very well. (Diversity of Intelligence Dimension) 
22. A girl says that thanks to her parents help and support, she was able to become an intelligent person. (People Dimension)

23. I have read in a blog that, as scientists say maturation ends in adolescence; intelligence cannot be improved beyond that moment. (Critical Period Dimension)

24. One of my teachers said: 'If your teachers support you to become intelligent, you'll end up being intelligent'. (People Dimension)

Jose Antonio Matias-Garcia, is a Predoctoral Fellow at the University of Seville, Faculty of Psychology, Department of Experimental Psychology. ORCID: https://orcid.org/0000-0002-38323804

Rosario Cubero-Pérez is an Associate Professor at the University of Seville, Faculty of Psychology, Department of Developmental and Educational Psychology. ORCID: https://orcid.org/0000-0002-16285392

Contact Address: jmatias@us.es 